\title{
Determining the potential of mobilephone-based health interventions in Kumasi, Ghana
}

Victor Stephani ${ }^{1}$, Daniel Opoku ${ }^{1}$ and Easmon Otupiri ${ }^{2}$

Ghana Med J 2020; 54(2): 88-92 DOI: http://dx.doi.org/10.4314/gmj.v54i2.6

${ }^{1}$ Department of Health Care Management, Technical University Berlin, Berlin, Germany

${ }^{2}$ School of Public Health, Kwame Nkrumah University of Science and Technology, Kumasi, Ghana

Corresponding author: Victor Stephani

E-mail: victor.stephani@tu-berlin.de

Conflict of interest: None declared

\section{SUMMARY}

Background: Numerous reviews have reported generally positive outcomes of mobile phone-based health (mHealth) interventions in the sub-Saharan African countries, especially for people with non-communicable diseases. At the same time, the mHealth landscape is burdened by a lack of sustainability. A recently published review has identified several context factors that influence the successful implementation of mHealth. Therefore, the aim is to use these contextual factors to assess the potential for mHealth in a particular clinical setting.

Design: The study used a cross-sectional, descriptive design.

Setting: The clinical setting of the study was the 'Komfo Anokye Teaching Hospital' in Kumasi, Ghana.

Participants: 150 patients attending the diabetes clinic were surveyed.

Main outcome measures: Context factors that influence the perceived usefulness and ease of use of mHealth.

Results: The survey revealed that patients at the diabetes centre had a positive attitude towards mobile phones, but also a low familiarity. Whereas patients faced several access barriers to care, most enabling resources for the successful and sustainable implementation of mHealth interventions such as access to mobile phones and electricity were available.

Conclusions: There is a high potential for mHealth in the setting of the diabetes clinic in Kumasi, Ghana.

Keywords: Ghana, mHealth, Diabetes, potential

Funding: None Declared

\section{INTRODUCTION}

The rapidly growing mobile phone infrastructure in subSaharan African (SSA) countries has led to the emergence of mobile phone-based health interventions (mHealth interventions) over the past decade. ${ }^{1-3}$ Numerous reports and reviews have reported that mHealth can have a positive effect on health outcomes, particularly for patients with non-communicable diseases (NCDs), such as Diabetes. ${ }^{4-6}$ While the body of evidence for the efficacy of such interventions is growing, the mHealth landscape is burdened by a lack of sustainability. Many interventions are not extended beyond the duration of the projectphase. ${ }^{7}$ Publications in the last years have therefore increasingly analysed why some interventions are more successful than others. ${ }^{8-10}$ It was illustrated that several contextual factors, e.g. the availability of reliable electricity infrastructure, heavily influence successful and sustainable implementation. ${ }^{11}$ However, many interventions were implemented without an analysis being made as to whether the respective context would be ready for mHealth. ${ }^{12,13}$

It is therefore important that future projects are only implemented after a preliminary analysis of the local context has been carried out. Therefore, the aim is to use contextual factors to assess the potential for mHealth in a particular clinical setting.

\section{METHODS}

\section{Study area}

The clinical setting of the study was a diabetes clinic, located at the Komfo Anokye Teaching Hospital (KATH) in Kumasi, Ghana. The KATH is a thousand-bed tertiary medical facility located in Kumasi (capital of the Ashanti Region) and serves a population of over 4.7 million. It is the second largest hospital in Ghana. ${ }^{14}$ The diabetic centre of the KATH is situated in the middle of the hospital campus. The appointments with the doctors of the diabetes clinic start from $9 \mathrm{AM}$ and end between 1 and $4 \mathrm{PM}$ and are usually conducted from Monday to Friday. 


\section{Study design}

A descriptive cross-sectional study was conducted among patients who attended the diabetes clinic at the KATH in 2017.

\section{Sample size and sampling methodology}

A hundred and fifty patients were recruited while waiting for their appointment at the clinic. The study was introduced and briefly explained in the local language (Twi) or English depending on the respondent's choice. After the introduction, patients were directly asked whether they are willing to participate. If they agreed, informed consent was obtained. The interviews were conducted in Twi or English, as the participant preferred.

\section{The questionnaire}

The questionnaire was designed based on the contextual factors from a recently published realist review, which has identified the mechanisms that explain why some mHealth interventions are likely to be more effective than others. ${ }^{11}$ The review is primarily based on Andersen's healthcare utilization model and describes the utilization and/or success of mHealth as a function dependent on predisposing characteristics, need and enabling factors (PNE factors). ${ }^{15}$

Predisposing factors are patients' cultural/social acceptance, attitude towards mobile technology, age, language, education level and their socio-economic background. For instance, if the target population has a very negative attitude towards mobile phones (predisposing characteristic), mHealth is not likely to improve care.

Need factors are barriers to care and patients' disease severity. For instance, if the disease severity is very low, it is not likely that the mHealth intervention is improving care.

Enabling factors are access to mobile phones, the availability of a functioning, stable telecommunication network, the assurance of privacy and support from partners/relatives. For instance, if there is no access to mobile phones, mHealth interventions cannot be used.

\section{Data collection instrument}

The questionnaire consisted of open-ended questions, as well as statements with a 5-point Likert-scale. The final questionnaire (supplementary file 1) was reviewed by all authors.

The Committee on Human Research, Publications and Ethics, of Medical Sciences, Kwame Nkrumah University of Science and Technology approved the questionnaire and the study protocol in September 2017 (Reference number: CHRPE/RC/229/17).

\section{RESULTS}

In total, 150 people with diabetes participated in the study; $72 \%$ were female and the majority $(83 \%)$ resided in urban areas. Patients had been living with the disease on average for 11.5 years. Most did not know which type of diabetes they have: $17 \%$ knew that they are diagnosed with Type 2 diabetes and $7 \%$ reported to have Type 1 diabetes.

\section{Predisposing characteristics:}

The predisposing characteristics of the patients from the diabetes clinic are depicted in Table 1. The results show that mobile phones were widely used in patients' communities and that the attitude towards mobile phones was very positive.

Table 1 Predisposing characteristics of patients with diabetes

\begin{tabular}{|c|c|c|c|c|c|}
\hline Parameter & \multicolumn{2}{|l|}{ n (\%) } & & & \\
\hline Age (years) & \multicolumn{2}{|c|}{$58(+/-10.32)$} & & & \\
\hline Speak English & \multicolumn{2}{|c|}{$105(70 \%)$} & & & \\
\hline Non-literate & \multicolumn{2}{|l|}{$64(43 \%)$} & & & \\
\hline Regular income & \multicolumn{2}{|l|}{$87(58 \%)$} & & & \\
\hline \multicolumn{6}{|l|}{ Education level: } \\
\hline None & \multicolumn{2}{|l|}{$27(18 \%)$} & & & \\
\hline Primary & \multicolumn{2}{|l|}{$40(27 \%)$} & & & \\
\hline Secondary & \multicolumn{2}{|l|}{$71(47 \%)$} & & & \\
\hline Tertiary & \multicolumn{2}{|l|}{$12(8 \%)$} & & & \\
\hline \multicolumn{6}{|l|}{$\begin{array}{l}\text { Main functions of } \\
\text { phone usage: }\end{array}$} \\
\hline $\begin{array}{l}\text { Calling and receiv- } \\
\text { ing }\end{array}$ & \multicolumn{2}{|l|}{$145(100 \%)$} & & & \\
\hline Texting & \multicolumn{2}{|l|}{$32(22 \%)$} & & & \\
\hline Internet & \multicolumn{2}{|l|}{$13(9 \%)$} & & & \\
\hline \multirow[t]{2}{*}{ Using apps } & \multicolumn{5}{|l|}{$22(15 \%)$} \\
\hline & $\begin{array}{l}1 \\
\text { Strongly } \\
\text { agree }\end{array}$ & $\begin{array}{l}2 \\
\text { Agree }\end{array}$ & $\begin{array}{l}3 \\
\text { Neither }\end{array}$ & $\begin{array}{l}4 \\
\text { Disa- } \\
\text { gree }\end{array}$ & $\begin{array}{l}5 \\
\text { Strong } \\
\text { ly disa- } \\
\text { gree }\end{array}$ \\
\hline $\begin{array}{l}\text { "Mobile phones are } \\
\text { very common and } \\
\text { widely used in my } \\
\text { community" }\end{array}$ & $102(68 \%)$ & $\begin{array}{l}43 \\
(28 \%)\end{array}$ & $3(2 \%)$ & $2(1 \%)$ & $0(0 \%)$ \\
\hline $\begin{array}{l}\text { "I am familiar with } \\
\text { using a mobile } \\
\text { phone" }\end{array}$ & $30(20 \%)$ & $\begin{array}{l}69 \\
(47 \%)\end{array}$ & $\begin{array}{l}30 \\
(20 \%)\end{array}$ & $\begin{array}{l}13 \\
(9 \%)\end{array}$ & $6(4 \%)$ \\
\hline $\begin{array}{l}\text { "I have a positive } \\
\text { attitude towards a } \\
\text { mobile phone" }\end{array}$ & $122(82 \%)$ & $\begin{array}{l}17 \\
(11 \%)\end{array}$ & $5(3 \%)$ & $4(3 \%)$ & $1(1 \%)$ \\
\hline
\end{tabular}

However, the familiarity with mobile phones appeared to be moderate. All patients knew how to make and receive calls, but only $22 \%$ were able to text with the phone, and only $9 \%$ were able to browse the internet. Patients were on average 58 years. The majority said that they received secondary school or higher level of education, but $43 \%$ stated that they could neither read nor write. English was spoken by two thirds of the patients; the other third spoke only Twi. 


\section{Needs}

On average, the patients needed almost 100 minutes to get to the diabetes clinic. They strongly agreed with the statement that the cost of the treatment is too expensive, and that adhering to the treatment is difficult.

Satisfaction with the availability of the health staff and overall treatment appeared to be moderate. Moreover, many reported that they suffer from complications due to their diabetes, and almost all (85\%) stated suffering from other diseases in addition to diabetes. Hypertension was the most often mentioned co-morbidity followed by eyeproblems and diseases such as typhoid or asthma. All need factors are depicted in Table 2.

Table 2 Needs of patients with diabetes

\begin{tabular}{|c|c|c|c|c|c|}
\hline Parameter & \multicolumn{5}{|l|}{ n (\%) } \\
\hline $\begin{array}{l}\text { Patients with co- } \\
\text { morbidities }\end{array}$ & \multicolumn{5}{|l|}{$128(85 \%)$} \\
\hline Distance between & \multicolumn{5}{|l|}{96.9} \\
\hline & $\begin{array}{l}1 \\
\text { Strongly } \\
\text { agree }\end{array}$ & $\begin{array}{l}2 \\
\text { Agree }\end{array}$ & $\begin{array}{l}3 \\
\text { Neither }\end{array}$ & $\begin{array}{l}4 \\
\text { Disagree }\end{array}$ & $\begin{array}{l}5 \\
\text { Strongly } \\
\text { disagree }\end{array}$ \\
\hline $\begin{array}{l}\text { "The cost of the } \\
\text { treatment is too } \\
\text { expensive" }\end{array}$ & $83(56 \%)$ & $32(22 \%)$ & $19(13 \%)$ & $10(7 \%)$ & $5(3 \%)$ \\
\hline $\begin{array}{l}\text { "Following and } \\
\text { adhering the dia- } \\
\text { betes-treatment is } \\
\text { difficult" }\end{array}$ & $60(40 \%)$ & $26(17 \%)$ & $3(2 \%)$ & $42(28 \%)$ & $18(12 \%)$ \\
\hline $\begin{array}{l}\text { "I suffer from } \\
\text { complications due } \\
\text { to my diabetes" }\end{array}$ & $60(40 \%)$ & $55(40 \%)$ & $14(9 \%)$ & $13(9 \%)$ & $7(4 \%)$ \\
\hline $\begin{array}{l}\text { "The diabetes } \\
\text { treatment is suffi- } \\
\text { cient and satisfies } \\
\text { all my health } \\
\text { needs" }\end{array}$ & $23(15 \%)$ & $53(36 \%)$ & $29(20 \%)$ & $28(19 \%)$ & $16(11 \%)$ \\
\hline $\begin{array}{l}\text { "The health staff } \\
\text { is always available } \\
\text { when I need } \\
\text { them" }\end{array}$ & $61(41 \%)$ & $18(12 \%)$ & $21(14 \%)$ & $37(25 \%)$ & $13(9 \%)$ \\
\hline
\end{tabular}

\section{Enabling resources}

Nearly $100 \%$ of the patients with diabetes had access to a mobile phone. The vast majority (91\%) owned a mobile phone, while $5 \%$ shared the phone with their family members. Forty-two (42\%) of the mobile phones were smartphones (phones capable of doing more than text messaging and making/receiving calls). Most agreed with the statement that there is always electricity to charge the phone. The mobile phone network was perceived as less reliable than the electricity network. In terms of the support by family and relatives, many patients assumed that they would receive their support when healthcare is delivered with a mobile phone. In case a phone is broken many reported that they would rather buy a new one than repair it.
One third mentioned that they cannot assure privacy on their phone, e.g. because family members have access to their phone (Table 3 ).

Table 3 Enabling resources for patients with diabetes

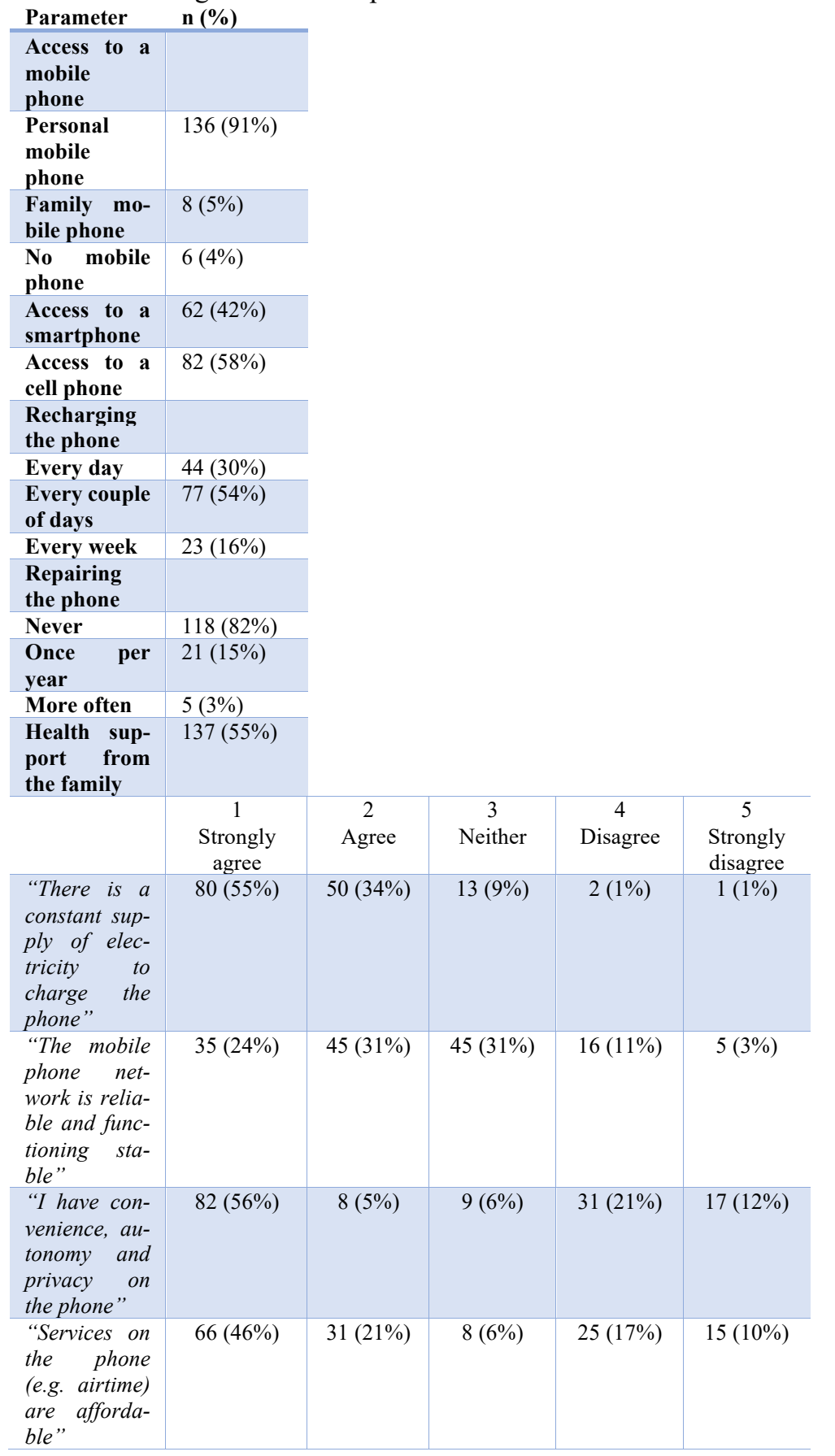




\section{DISCUSSION}

This is the first study which determined the potential of mHealth by using PNE factors. In the case of the diabetes clinic in Kumasi, Ghana it turned out that the predisposing characteristics (e.g. high acceptance of mobile phones in the community, positive attitude towards mobile phones), the higher need (e.g. patients faced several access barriers to care, suffered from diseases beside of their diabetes) and the availability of the enabling resources (e.g. access to mobile phones, electricity) would translate into a high potential for future mHealth interventions.

The study provides important findings on several factors specific to the patients from the diabetes clinic in Kumasi and shows therefore the importance of such a preliminary analysis: First, the subscription rate at the Diabetes clinic (meaning the share of people who have access to a phone) was nearly $100 \%$. This is higher than average subscription rates in Ghana (67\%). ${ }^{16}$ A mobile phone-based health interventions would, therefore, be able to include almost all patients from the clinic.

Second, $42 \%$ of the patients had access to smartphones (phones capable of using third party applications and browsing the internet). This is higher than the total average in SSA (34\%). ${ }^{16}$ This bears opportunities for future mHealth interventions, since the ability to provide information via applications, in combination with voice calls or text messages, is perceived as a key to improving the situation of patients and their access to care. ${ }^{17}$

Third, despite high cultural and social acceptance of the mobile technology, the familiarity with mobile phones turned out to be low. This could be due to the higher average age of the here analysed community. Elderly people tend to have a lower familiarity with the full spectrum of all mobile phone functions. ${ }^{18}$ However, a low 'phone literacy level' needs to be considered when implementing an intervention.

Providers need to ensure, that the patients are capable of using all, or at least most, functions of the intervention. This may require workshops or training-lessons which would also improve patients' overall ability to use the mobile phone as a tool to research, organize, evaluate and communicate information. ${ }^{19}$

The analysis has implications for policy makers, researchers and industry representatives who are involved in the development of mHealth solutions. The approach could be adapted and utilized in order to identify regions with a higher potential for mHealth.
If a region qualifies for mHealth (such as the diabetes centre at KATH), prototypes of particular interventions (e.g. an appointment reminder system via SMS) could be developed and tested.

Furthermore, some aspects, such as the identified low familiarity with mobile phones, could be already considered during implementation-phase. This 2-step approach (feasibility analysis plus large-scale study with prototypes) could be used as a cookbook towards a more sustainable implementation of mHealth. And it would therefore counteract the widespread problem that many mHealth interventions have not moved beyond the pilot phase.

\section{Strengths and limitations of the study}

A major strength of the study is that the analysis and the questionnaire are scientifically grounded. ${ }^{11}$ However, other factors such as an enabling legislation or the planning and funding of the project-stakeholders, might also have a significant influence on a successful implementation and were not considered in this analysis.

Another limitation of the study is its sample size and its selection. The sample was conveniently selected, and those patients were studied who were available at the time of the survey. However, the study was meant to be an exploratory study as no other related study could be found in the Ghanaian context. For a more representative sample more people would have to be interviewed over a longer period of time. A further limiting factor could have been that all outcome parameters are self-reported. Some parameters may be therefore biased, e.g. self-reported familiarity with mobile phones or the distance to the clinic. However, the interviewer tried to avoid this bias by explaining and repeating a question, when it was needed.

Finally, the study included only patients who have been diagnosed with diabetes and have already been to the diabetes clinic in Kumasi. It is estimated that two thirds of all people with diabetes remain undiagnosed and have therefore never attended a diabetes clinic. The identified potential does therefore only count for the patients of the diabetes clinic at KATH and cannot simply be transferred to other population-groups.

\section{CONCLUSION}

It has been successfully demonstrated how the potential of mHealth can be measured in a particular environment. In the case of diabetes patients from Kumasi, Ghana, the potential was shown to be high. Thus, mHealth interventions would most likely work for these patients. 


\section{ACKNOWLEDGEMENT}

The authors want to thank Dr. Roderick Larsen-Reindorf from KATH for his support in conducting the field-work. Furthermore, the authors thank the entire team at the KATH diabetes center for giving us the opportunity to conduct the research.

\section{REFERENCES}

1. Organization WH. Global Observatory for eHealth. Atlas of eHealth country profiles: the use of eHealth in support of universal health coverage: based on the findings of the third global survey on eHealth 2015. Geneva: WHO; 2016.

2. Lee S, Cho Y-m, Kim S-Y. Mapping mHealth (mobile health) and mobile penetrations in sub-Saharan Africa for strategic regional collaboration in mHealth scale-up: an application of exploratory spatial data analysis. Global Health. 2017;13(1):63.

3. Intelligence GA. The Mobile Economy: Sub-Saharan Africa 2018. United Kingdom: GSMA Head Office; 2018.

4. Bloomfield GS, Vedanthan R, Vasudevan L, Kithei A, Were M, Velazquez EJ. Mobile health for noncommunicable diseases in Sub-Saharan Africa: a systematic review of the literature and strategic framework for research.Global Health. 2014;10(1):49.

5. Beratarrechea A, Lee AG, Willner JM, Jahangir E, Ciapponi A, Rubinstein A. The impact of mobile health interventions on chronic disease outcomes in developing countries: a systematic review. Telemedicine and e-Health. 2014;20(1):75-82.

6. Stephani V, Opoku D, Quentin W. A systematic review of randomized controlled trials of mHealth interventions against non-communicable diseases in developing countries. BMC Public Health. 2016;16(1):572.

7. BMZ. Digital Health Ecosystem for African countries: A Guide for Public and Private Actors for establishing holistic Digital Health Ecosystems in Africa. Federal Ministry for Economic Cooperation and Development (BMZ); 2018.

8. Franz-Vasdeki J, Pratt BA, Newsome M, Germann S. Taking mHealth solutions to scale: enabling environments and successful implementation. $J M o b$ Technol Med. 2015;4(1):35-8.

9. Aranda-Jan CB, Mohutsiwa-Dibe N, Loukanova S. Systematic review on what works, what does not work and why of implementation of mobile health (mHealth) projects in Africa. BMC public health. 2014;14(1):188.

10. Leon N, Schneider H, Daviaud E. Applying a framework for assessing the health system challenges to scaling up mHealth in South Africa. BMC Med Inform Decis Mak. 2012;12(1):123.

11. Opoku D, Stephani V, Quentin W. A realist review of mobile phone-based health interventions for noncommunicable disease management in sub-Saharan Africa. BMC Med. 2017;15(1):24.

12. Collins F. How to fulfill the true promise of" mHealth": Mobile devices have the potential to become powerful medical tools. Scientific American. 2012;307(1):16.

13. Lemaire J. Scaling up mobile health: Elements necessary for the successful scale up of mHealth in developing countries. Geneva: Advanced Development for Africa. 2011.

14. 16. KATH. Webpage of the KATH 2018 [updated 05/29/2018. Available from: http://www.kathhsp.org/about.html.

15. Andersen RM. Revisiting the behavioral model and access to medical care: does it matter? J Health Soc Behav. 1995:1-10.

16. GSMA. The Mobile Economy: Sub-Saharan Africa 2017 [Available from: https://www.gsmaintelligence.com/research/?file=7bf3592e6d750144e58d9dcfac6adfab\&download

17. GSMA. The Mobile Economy 2016 [Available from: https://www.gsma.com/mobileeconomy/archive/GSMA_ME_2016.pdf.

18. Hardill I, Olphert $\overline{\mathrm{C} W}$. Staying connected: Exploring mobile phone use amongst older adults in the UK. Geoforum. 2012;43(6):1306-12.

19. Irvin R. Information and communication technology (ICT) literacy: Integration and assessment in higher education. J Syst Cybern Inf. 2007;5(4):50-5. 